\title{
The complexity of 'harm reduction' with smokeless tobacco as an approach to tobacco control in low-income and middle-income countries
}

\author{
Olalekan A Ayo-Yusuf, ${ }^{1,2}$ David M Burns ${ }^{3}$
}

${ }^{1}$ Department of Community Dentistry, Faculty of Health Sciences, University of Pretoria, Pretoria, South Africa ${ }^{2}$ Center for Global Tobacco Control, Department of Society, Human Development and Health, Harvard School of Public Health, Boston, Massachusetts, USA

${ }^{3}$ UCSD School of Medicine, San Diego, California, USA

\section{Correspondence to}

Professor Olalekan A Ayo-Yusuf, Department of Community Dentistry, Faculty of Health Sciences, Oral and Dental Hospital, University of Pretoria, PO Box 1266, Pretoria 0001 South Africa;

lekan.ayoyusuf@up.ac.za

Accepted 6 December 2011
ABSTRACT

Objective To review the implications of recommending

smokeless tobacco (ST) use as a harm reduction approach for low-income and middle-income countries (LMICs).

Method Narrative review of published papers and other data sources (including conference abstracts and internet-based information) on the health risks posed by the use of ST products for individual smokers and for the population with a focus on their implications for LMICs. Results Swedish snus has a relatively lower toxicity profile than ST products available in other markets, including older products used in the US and products used in Africa and Asia. The experience with snus in Sweden provides information on the effects of snus use in a population where cigarette smoking was already culturally ingrained. However, population effects are likely to be different in those LMICs where smoking is not yet the dominant culturally accepted form of tobacco use. The total effect may be negative in countries where locally-popular ST products have substantially higher disease risks than Swedish snus and where there is limited regulatory and tobacco use surveillance capacity. Conclusions Issues relating to how populations in LMICs respond to marketing efforts, the risks of the dual use of ST and smoking, and the capacity to regulate ST products need to be considered in making decisions about harm reduction strategies in LMICs. The public health effects of supporting ST as a harm reduction strategy may vary substantively in countries with different pre-existing tobacco use patterns.

\section{INTRODUCTION}

Globally, tobacco use currently accounts for just over 5 million deaths annually, a number expected to increase to over 8 million deaths annually by $2030 .^{1}$ It is predicted that $70 \%$ of these future deaths will occur in low-income and/or middleincome countries (LMICs). The increase in future deaths is expected to be largely due to increased cigarette use; however, smokeless tobacco (ST) use accounts for a substantial number of deaths, including about 60000 deaths annually on the Indian subcontinent alone. ${ }^{2}$

Cigarette smoking prevalence has decreased over the last two decades in most high-income countries, but continues to increase in several LMICs. ${ }^{3}$ The principal tobacco control strategies articulated in the WHO Framework Convention on Tobacco Control (FCTC) include preventing tobacco use initiation, promoting cessation and protecting non-smokers from the adverse health effects of secondhand smoke. ${ }^{4}$ Nevertheless, there continue to be new tobacco users and established tobacco users who are unable or unwilling to quit. ${ }^{6}$ The continuing, and in some countries expanding, prevalence of cigarette smoking has led to a broadening of traditional tobacco control strategies to include 'harm reduction' approaches such as considering the use of ST as a means of reducing the use of combusted tobacco products.

Several papers describe the challenges of tobacco harm reduction even in developed countries, notably the US and Sweden. ${ }^{6-11}$ This paper intentionally avoids a detailed consideration of the value and risks of recommending ST use in developed countries. Instead it focuses on the differences in the circumstances and patterns of use in LMICs and how they might influence policy considerations about ST use in those countries.

\section{CONCEPTS OF TOBACCO 'HARM REDUCTION'}

Broadly speaking, all tobacco control strategies can logically be defined as 'harm reduction' strategies, since avoiding tobacco use reduces risks, but the contemporary usage of the term refers specifically to the objective of minimising the net damage to health for continuing tobacco users and the general population by substituting less harmful tobacco products for more harmful ones, particularly cigarettes. $^{8}$ There is sometimes a dynamic tension where changes that may benefit some individuals (eg, switching from cigarettes to low nitrosamine ST) may bring about changes that may injure others in the population (eg, an increase in adolescents taking up ST, who then switch to cigarettes because of the marketing of ST). This may require a balancing of different forms of harm. ${ }^{12-15}$ This balance may be quite different in LMICs than in wealthier countries, and may well be different for different LMICs. What may reduce harm in one country or a subpopulation within a country may create harm in another.

Much of the evidence supporting ST use as a harm reduction approach aimed at reducing use of combusted products comes from men in Sweden and a few other higher-income countries. In these countries, smoking has been the dominant form of tobacco use and the formulation of some of the ST products displays a lower risk profile than that of many ST products widely used in parts of Africa and Asia. ${ }^{16-21}$ The overall disease risks resulting from ST use are indeed lower than those for smoking cigarettes, and, in the case of currently available low-nitrosamine ST products such as the snus used in Sweden, there are dramatically lower 
oral cancer risks. Swedish 'snus' refers to a moist snuff tobacco product prepared by heat treating, rather than fermenting, the tobacco; it has relatively low levels of carcinogenic tobaccospecific nitrosamines, polycyclic aromatic hydrocarbons and heavy metals, compared with ST products from other parts of the world. ${ }^{22} 23$ The distinctive manufacturing process of the Swedish snus and its storage in refrigerators until sold is thought to be responsible for the lower levels of carcinogenic nitrosamines in these products. ${ }^{7}$ Swedish snus has a cancer risk profile that is substantially lower than the ST products available in other markets, including the older products used in the USA, and its cancer risk profile is markedly lower than that of most of the ST products commonly used in Asia or Africa. ${ }^{16-21} 24$

\section{EVIDENCE OF DISEASE RISKS AT INDIVIDUAL LEVEL}

ST use has been associated with oral, oesophageal and pancreatic cancer. ${ }^{24}$ However, most available evidence suggests that ST products currently on the Swedish market are not associated with a significantly increased risk for oral cancer. ${ }^{24} 25$ There is also little evidence to suggest that ST use increases the risk of lung cancer or chronic obstructive pulmonary disease. ${ }^{24} 25$ The magnitude of the risk and the disease pattern for those risks differ markedly for the formulations of ST products used in different geographical locations. ${ }^{21} 26$ The formulations of ST used in parts of Africa and Asia, notably in the Sudan and India, produce very high risks for oral cancer and some other cancers and are responsible for a substantial proportion of the tobacco-related morbidity and mortality in these areas. ${ }^{24}$

Findings from recent meta-analyses ${ }^{27} 28$ on the cardiovascular risk associated with ST use, and even more recent studies in the USA and Sweden, ${ }^{29}{ }^{30}$ suggest that the risk of myocardial infarction is low or not evident for Swedish snus type products. However, an increased risk for fatal and non-fatal strokes has been more consistently demonstrated with ST use, albeit with a lower risk for snus use. The overall RR for stroke associated with formulations of ST used in developed countries is estimated to be between 1.20 and $1.40,{ }^{27} 28$ a risk which is substantively lower than the risk levels associated with smoking $(R R=2.5)$. In marked contrast, the cardiovascular risk posed by ST use in populations in 52 countries, including India, other Asian countries and African countries, includes a risk of myocardial infarction for ST users that is only slightly lower than that for cigarette smokers, suggesting that the cardiovascular risks for ST products may vary substantially according to the product, particularly in LMICs. ${ }^{31}$

The use of snus in Sweden and of ST in India has been associated with adverse reproductive health outcomes. ${ }^{32-34}$ In South Africa, ST use has been associated with significantly reduced gestational age, but not with low birth-weight babies. ${ }^{35}$ A recent African study associated ST use with a precursor lesion for cervical cancer. ${ }^{36}$

The enormous range of toxicities seen with different formulations of ST use make it inappropriate to treat all forms of ST use as equivalent in harm reduction discussions. The reality for many LMICs is that the ST products most likely to be used are more hazardous indigenous forms rather than those with risks equivalent to Swedish snus. This makes recommending ST use as a harm reduction strategy a much more complex, and potentially hazardous, policy choice in LMICs.

\section{IMPACT ON SMOKING INITIATION AND EFFECTIVENESS AS A CESSATION AID}

Much of the debate emphasising ST use as a harm reduction strategy focuses on whether it serves as a gateway in to or out of cigarette smoking. While some evidence suggests that ST use is a gateway into smoking in the USA, ${ }^{37-40}$ studies from Sweden suggest that snus use is associated with a lower likelihood of daily smoking among adolescents. ${ }^{10} 1141$ These differences may be due to cultural differences in the influence of ST on smoking initiation in adolescents, differences in public policy (eg, differential taxation and thus the pricing of different forms of tobacco) and/or differences in tobacco industry marketing strategies used in these two countries. Only limited data are available on the role of ST in smoking initiation outside the USA and Sweden; however, preliminary South African findings suggest that ST use may be a significant predictor of adolescent smoking uptake. ${ }^{42}$ More cohort studies are needed in nonWestern countries with significant ST use.

Cross-sectional studies in Sweden suggest that snus may be at least twice as effective in helping smokers quit than medicinal nicotine formulations. ${ }^{11} 43$ However, the only randomised controlled trial comparing both product types as cessation interventions failed to show any significant difference using the standard 6-month outcome measure of abstinence. ${ }^{44}$ Most crosssectional studies in Sweden use self-reports of daily smoking, making it possible for daily smokers who have become intermittent smokers to be classified as quitters. The difference between the findings of the controlled trial and those of the cross-sectional studies may therefore be partly explained by differences in the outcome measures used, for example, longterm intermittent smoking was reported as more common among snus users. ${ }^{45}$

Several studies suggest that at least $70 \%$ of ex-smokers in Sweden, especially women, did not use snus to quit, ${ }^{46-48}$ suggesting that other tobacco control efforts are likely also to have contributed to the decline in smoking prevalence. There is a need for well controlled follow-up studies to elucidate the impact of ST use on smoking cessation in LMICs.

\section{DUAL USE CONCERNS}

There is some concern that the cigarette industry has entered the ST market to promote the situational use of ST by smokers rather than to promote cessation of the use of smoked products. $^{49} 50$ Recent US studies suggest that smokers currently unwilling to make a quit attempt are more likely to use alternative products for partial substitution, rather than for complete substitution. 5051

Dual use seems to be more common among younger adults than among older adults in the USA ${ }^{52}$ and in South Africa. ${ }^{54}$ Recent national and regional studies from other LMICs such as India, ${ }^{55}$ Nigeria $^{56}$ and Uzbekistan ${ }^{57}$ also suggest that as many as $20 \%$ of adult ST users also smoke concurrently. The Swedish situation is less clear, but recent national long-term follow-up data on the pattern of tobacco use among the Swedish middleaged population suggest that dual use is also a concern there, particularly among those with lower educational attainment. ${ }^{58}$ Although past adult surveys in Sweden suggest that only $10 \%$ of daily snus users also smoke daily, ${ }^{48} 59$ a recent cohort study suggests that as many as $45 \%$ of exclusive snus users became dual users 10 years later. ${ }^{58}$ Some argue that dual use could be the transition period to eventually taking up exclusive ST use or quitting all tobacco use. However, the recent findings from Sweden suggest that about a third of dual users remained dual users after 10 years. ${ }^{58}$ More longitudinal data on the trajectory of dual use outside of Sweden are still needed.

Whatever the trajectory of dual use, a more important issue is estimating the extent to which dual use contributes to harm 
reduction. A recent published review by industry scientists concluded that the health outcomes for dual users are no worse than those associated with exclusive smoking. ${ }^{60}$ In fact, other than a reduced risk for cancer, the data suggest that there is no risk reduction for cardiovascular diseases, particularly strokes. As previously noted, a large cross-country study that included products from LMICs demonstrates a significantly higher risk for myocardial infarction among those who smoke and chew concurrently, compared to those who only smoke. ${ }^{31}$ Others have suggested that dual users have a higher degree of dependence ${ }^{52} 61$ and a steeper trajectory and more prolonged tobacco consumption than exclusive users of either only snus or only cigarettes. ${ }^{61}$ Based on the evidence and key inputs to modelling approaches ${ }^{12}$ used in estimating the harm reduction potential of promoting ST use as a strategy, dual use poses a significant threat to the harm reduction goal, particularly in the unregulated markets found in many LMICs, where members of the public may not be able to distinguish between the risk profiles of Western-style ST brands and those of local brands or where the local brands may be used concurrently with cigarette smoking.

The harm reduction potential for ST, or any other alternative nicotine-delivery product, depends largely on the change in the net number of smokers: how many confirmed smokers switch to ST products as opposed to the number of additional cigarette smokers created by first using ST and then switching to cigarettes. Hence, the receptivity of smokers to products and the marketing of products to adolescents are important. ${ }^{62-65}$ The capacity to continuously monitor how the population responds to marketing efforts is therefore also an important consideration.

\section{PRODUCT MARKETING AND COMIMUNICATION OF RISK}

The experience in Sweden is quite different from that in other countries where ST use has been widespread, including Norway and the USA. In the US, ST has been widely marketed since the 1970s, but marketing efforts have largely focused on young men. ${ }^{66}$ It is likely that, as a result, ST use has been confined largely to young men, with little evidence of dependent adult smokers shifting to ST as a harm reduction effort. ${ }^{67}$ This observation suggests that a replication of the Swedish experience may depend on the marketing messages used, and that the Swedish experience may be the result of non-generalisable cultural factors. At the very least, the decision to encourage the use of ST as a harm reduction strategy in LMICs must be accompanied by close attention to the marketing strategies used for these products, and we must exercise caution in assuming that all countries will have the same cultural response as Sweden did.

Regulations regarding the marketing messages communicated about ST use for harm reduction are needed, since the industry's current marketing practices in some LMICs ${ }^{68} 69$ and highincome countries have raised concerns. ${ }^{12} 49$ Practices suggesting an industry strategy to use ST harm reduction messages as a public relations ploy, while continuing to aggressively promote cigarette use, include cross-branding ST products with known cigarette brands, ${ }^{12}{ }^{49}$ extending marketing to media channels not necessarily restricted to smokers ${ }^{70}$ and promoting situational use. $^{12} 4971$ There is concern that the communication of RR to consumers, while important, may be used to subvert comprehensive advertising bans in several countries that are parties to the WHO's FCTC. ${ }^{72}$ The differences in disease risks for formulations of ST used in LMICs also raise questions about appropriate educational messages about ST use and suggest that regulatory control regarding the risk profile for the products that are allowed to be marketed should be a critical component of any harm reduction strategy in LMICs.

The industry has been able to communicate with smokers in South Africa about snus using information leaflets at points of sale to describe how to use the products and the advantages of using snus, including claims that the product 'helps to reduce or quit smoking' and comments such as 'you can enjoy it when you cannot smoke' (figure 1). This 'natural experiment' that started in South Africa during 2005, as with a similar effort in India during 2002, ${ }^{68}$ appears to have failed, as snus use remains negligible, even though the use of traditional snuff by indigenous non-smoking women remains high in both these countries. ${ }^{55} 73$ The failed South African and Indian 'experiments' with snus are further evidence that the Swedish experience may not be transferable to other cultures. ${ }^{20}$ A recent survey among Uzbekistan adults also suggests that very few $(<5 \%)$ smokers are willing to switch to ST, even if cigarette prices double. $^{57}$

\section{APPLYING THE EVIDENCE OF REDUCED RISK AT POPULATION LEVEL IN LMICS}

National death rates in Sweden demonstrate a dramatic decrease in male cigarette smoking prevalence and resultant male lung cancer rates over the last few decades. ${ }^{10}$ This decline in prevalence is associated with increased ST use by Swedish males. Considerable evidence suggests that the increased use of ST was a substitute for cigarette smoking and may therefore be responsible for part of the decline in the male smoking prevalence and lung cancer rates in Sweden. ${ }^{10}$ However, some challenge this assertion, ${ }^{74}$ arguing that the observed smoking rate decrease among Swedish men since the early 1960s is a response to a range of tobacco control measures introduced in Sweden. ${ }^{74-76}$ The drop in lung cancer rates among Swedish males is the strongest evidence to date for the use of ST as a harm reduction approach at a population level, but several caveats are important in applying this evidence to LMICs.

Switching from daily cigarette use to exclusive ST use clearly offers individual smokers a significant health gain, but the magnitude of the population benefit depends on the product used and the pattern of use, both of which may differ in terms of the consideration of costs and benefits for LMICs. The population impact of ST for tobacco harm reduction is defined as the difference in risks between cigarette smoking and ST use (depending on ST formulation) and as the effect of policies encouraging ST use as a harm reduction strategy on the number of future cigarette smokers and the total burden of tobaccorelated diseases.

The potential positive population impact includes:

- A reduction in the initiation of cigarette smoking by substituting the initiation of ST use.

- A delay in the initiation of cigarette smoking by first use of ST.

- Reductions in the number of smokers derived from switching to ST exclusively.

- Reductions in the frequency and intensity of cigarette consumption by substituting ST use for some cigarettes during dual use.

- Switching to ST in ways that ultimately lead to abstinence from all tobacco products.

Adverse population impacts on cigarette use includes:

- The initiation of cigarette use among ST users who would not have become cigarette smokers had they not first used ST. 

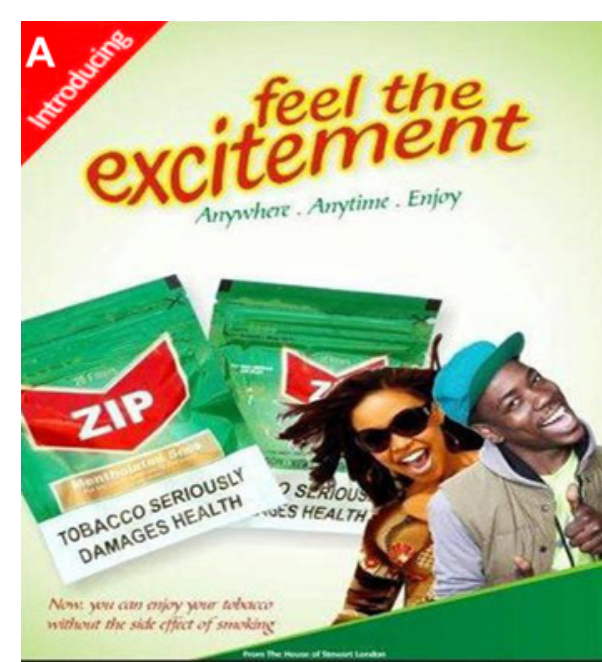

TOBACCO SERIOUSLY DAMAGES HEALTH

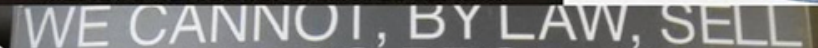

D TOBACCO' PRODUCTS TO ANYONE UNDER THE AGE OF 18 YEARS

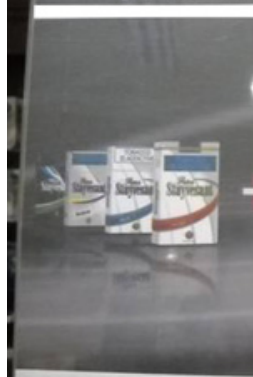

DANGER:

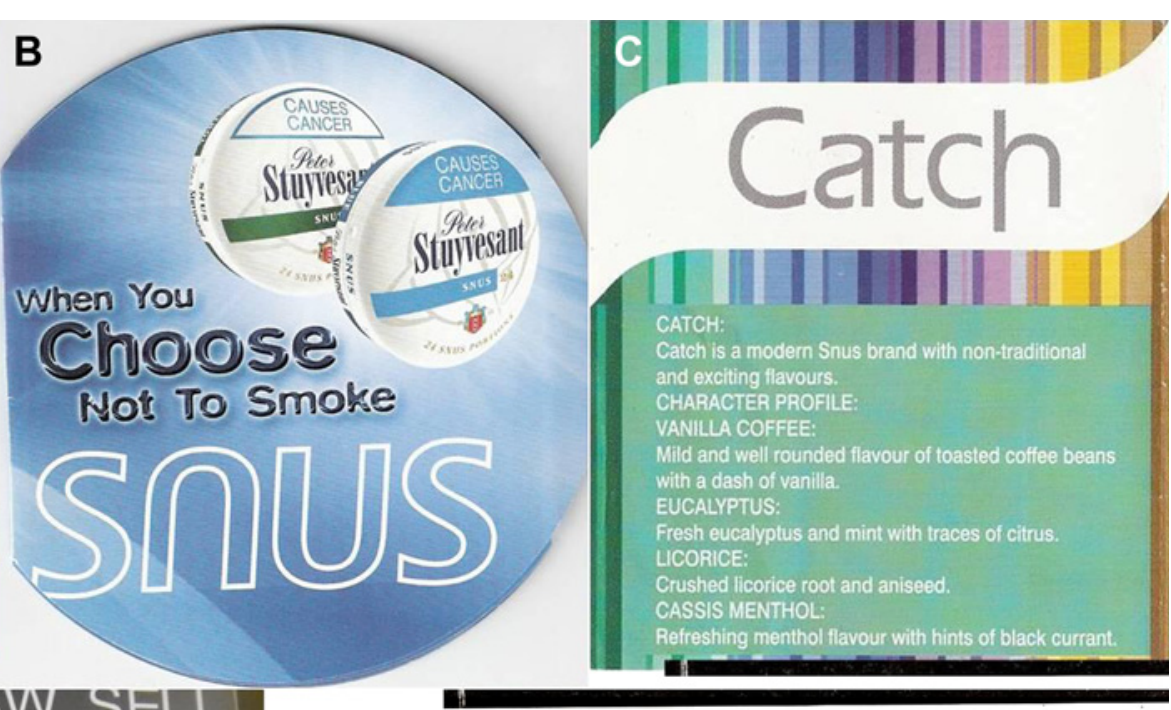

E WHY SHOULD I USE SNUS?

- It is safer than smoking.

- Helps to reduce or Quit Smoking.

- Smoke free tobacco does not disturb others.

- No Smoke inhalation.

- It is discreet.

- Virtually invisible once in your mouth.

- It is the modern smokeless alternative.

- Socially acceptable.

- You can do it Anywhere.

- No Secondhand smoke.

- You can enjoy it when you cannot smoke.

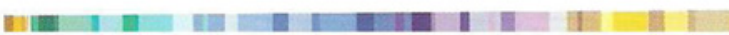

Figure 1 Promoting snus for situational use in Nigeria (A) and South Africa (B-E).

- A delay or deferral of smoking cessation because of conflicting messages on the hazards of tobacco use or as the result of the dual use of smokeless and smoked tobacco products.

- Reduced cessation by smokers who use ST products to try to quit and who fail, when other approaches might have led to abstinence.

- Reduced benefits from restrictions on where smoking is allowed on the intensity of addiction and likelihood of cessation by the use of ST in settings where smoking is not allowed.

- The continued use of ST among individuals who would otherwise have quit all forms of tobacco use (this may be a particular concern for geographic areas where the forms of ST used pose relatively high disease risks).

The balance of these effects for population harm may indeed be different for LMICs. Again, a principal difference likely to be present is the substantially greater disease risks observed for specific formulations of ST used in many LMICs, but there are also other differences that should be considered, based on the stage of the tobacco epidemic and the existing patterns of use in those countries.

Some of the poorest LMICs are in an early stage of the tobacco epidemic and do not yet have many individuals who have been addicted to nicotine for a very long period and wish to quit, but have been unable to quit, despite the implementation of comprehensive tobacco control policy and clinical interventions. Several LMICs also still have a relatively lower burden of lung cancer attributable to smoking, but have a high burden of cardiovascular diseases that have been associated with cigarette smoking and ST use (table 1). The initiation rates of cigarette smoking are only beginning to grow in these LMICs, and therefore there are few adult smokers who can be encouraged to switch to ST. In some of these countries, there is also little current use of ST, particularly in countries where tobacco is not grown in substantial quantities. For these countries, the issue is prevention rather than harm reduction; and the questions include how to prevent the initiation of cigarette smoking and how to avoid the introduction and use of formulations of ST with high disease risks. In the absence of a pre-existing social tradition of tobacco initiation and nicotine addiction, the risk that promoting ST use may increase smoking uptake by acting as a gateway behaviour may outweigh its potential to decrease smoking as an alternate form of tobacco use.

The experience in Sweden relates to a population where heavy cigarette smoking prevalence among adult men was well established, and smoking was culturally ingrained in the population. Even if one agrees that the introduction of snus use produced the decline noted in the adult male smoking prevalence in Sweden, the Swedish experience may not apply to populations in many African countries where male cigarette smoking 
Table 1 Age-standardised death rates from three leading tobaccorelated causes of death during 2004

\begin{tabular}{lclc}
\hline & \multicolumn{3}{l}{ Death rate (per $\mathbf{1 0 0 0 0 0}$ persons/year) } \\
\cline { 2 - 4 } WHO region & $\begin{array}{l}\text { Respiratory } \\
\text { diseases }\end{array}$ & $\begin{array}{l}\text { Cardiovascular } \\
\text { diseases }\end{array}$ & $\begin{array}{l}\text { Lung } \\
\text { cancer }\end{array}$ \\
\hline Africa & 92 & 390 & 8 \\
South-East Asia & 98 & 365 & 14 \\
Eastern & 61 & 458 & 12 \\
Mediterranean & & & \\
Western Pacific & 103 & 243 & 29 \\
Americas & 41 & 202 & 27 \\
European & 26 & 332 & 29 \\
World & 71 & 301 & 23 \\
\hline
\end{tabular}

Data source: WHO Global Burden of Disease survey, 2004 (https://apps.who.int/infobase/ Mortality.aspx? =\&Group1 =RBTCntyByRg\&DDLCntyByRg =EUR\&DDLCntyName $=1004 \&$ DDLYear $=2004 \&$ TextBoxImgName $=$ go).

prevalence is low, and in other LMICs, where the dominant form of tobacco used by the largest population groups is already ST of high toxicity. ${ }^{17} 7377$ For example, it is not clear that encouraging snus use in a population such as that in Nigeria (the most populous nation in Africa, where smoking is not yet culturally ingrained) will prevent the adoption of cigarettes as the dominant form of tobacco use as the population responds to continued cigarette marketing efforts. Endorsing ST products as posing a lower risk may confuse and blunt current efforts, including effective mass media campaigns, ${ }^{78}$ aimed at dealing with the substantive existing disease occurrence resulting from the use of indigenous smokeless products. In addition, even in Sweden there has not been a substantial effect on female smoking prevalence, raising questions about the applicability of encouraging ST use in populations such as those in India, Bangladesh, Cambodia, Mauritania and South Africa, ${ }^{79}$ where there are already a substantial number of female ST users, but smoking prevalence among women is low (table 2).

Finally, in the absence of regulatory control that can successfully address the toxicities introduced by the practices of small local producers, any shift to ST use is likely to be to the indigenous forms of high toxicity ST, rather than to Swedish-

Table 2 Current smoking prevalence in countries of the world with available data showing substantial smokeless tobacco use prevalence $(\geq 10 \%)$ either among adult men or women

\begin{tabular}{lllllc}
\hline & Men & & & Women \\
\cline { 2 - 3 } \cline { 5 - 6 } Country & Smokeless tobacco & Smoking & & Smokeless tobacco & Smoking \\
\hline Algeria & 10.4 & 33.9 & & 0.8 & 2.4 \\
Benin & 12.7 & 15.8 & & 5.7 & 1.4 \\
Mauritania & 5.7 & 34.1 & & 28.3 & 5.7 \\
South Africa & 2.4 & 27.5 & & 10.9 & 9.1 \\
Bangladesh & 26.4 & 44.7 & & 27.9 & 1.5 \\
Bhutan & 21.1 & 8.4 & & 17.3 & 4.7 \\
India & 32.9 & 24.3 & & 18.4 & 2.9 \\
Myanmar & 51.4 & 44.7 & & 16.1 & 7.8 \\
Nepal & 31.2 & 34.5 & & 4.6 & 15.9 \\
Sri Lanka & 24.9 & 29.9 & & 6.9 & 0.4 \\
Norway (HIC) & 17.0 & 31 & & 5.0 & 28 \\
Sweden (HIC) & 26.0 & 25 & & 7.0 & 23 \\
Uzbekistan & 22.5 & 20 & & 0.4 & 1.1 \\
Yemen & 15.1 & 35 & & 6.2 & 13 \\
Cambodia & 0.7 & 39.1 & & 12.7 & 3.4
\end{tabular}

Data source ${ }^{79}$ : WHO Report on the Global Tobacco Epidemic (http://www.who.int/tobacco/ global_report/2011/full_dataset/en/index.html).

HIC, high-income country.

\section{What this paper adds}

There is a growing interest in using smokeless tobacco (ST) products for tobacco harm reduction, notably in the USA and Sweden, but only limited information is available on its implications for tobacco control in low-income and middleincome countries (LMICs).

- This review suggests that considering the existing widespread use of low-cost ST products of relatively high toxicity in several LMICs, the limited capacity for product regulation and the priority goal of preventing smoking uptake in several LMICs in the early stage of the epidemic, there is insufficient evidence to endorse the harm reduction approach of promoting ST products as an effective global tobacco control strategy.

style products manufactured to have low toxicity. In fact, the potential for stimulating the local manufacture of high risk ST formulations by small producers, rather than use of snus similar to that used in Sweden, is likely to be high, given the low income and limited regulatory capacity of these countries. The reality is that, even if snus is priced cheaper than cigarettes as a policy initiative to encourage smokers to switch to snus, it is not likely to be cheaper than existing indigenous forms of ST products or even highly discounted cigarettes (eg, in China) $)^{80}$ that are currently available to local populations. Nevertheless, state control over tobacco production in countries such as China may provide a unique opportunity for tobacco harm reduction if the state were to completely replace cigarette production with the manufacture of low-risk ST formulations.

Other LMICs have a substantial existing prevalence of cigarette smoking and ST use, notably among adult men in India, Myanmar and Bangladesh, and the risks generated by use of the existing ST formulations are much closer to those of cigarettes than are the risks of ST products used in Europe and the USA. The magnitude of the risks associated with these traditional ST formulations are large enough for even modest increases in the total tobacco use in the population (even as ST) or small declines in the rate of cessation of either cigarette or ST use to cancel out the population benefit of individuals switching from cigarettes to ST use.

\section{CONCLUSIONS}

Many of the circumstances that could make the recommendation of ST use for harm reduction a potentially feasible option for wealthy countries are either not currently present or are substantively different for LMICs. Bearing in mind the importance of regulation as a precondition for achieving the goals of harm reduction, and the generally weak tobacco control policy environments that currently exist in most LMICs, the potential public health benefits that might accrue from harm reduction approaches based on converting smokers to ST use are unlikely to be large enough to convince policymakers to ignore the potential unintended consequences of doing so.

Acknowledgements We thank Bukola Olutola, University of Pretoria, for help with the literature search. The opinions expressed in this paper are those of the authors and does not in any way represent the position of the organisation(s) they represent.

Competing interests DMB has testified extensively as an expert in litigation against the tobacco industry. 
Contributors OAA-Y wrote the first draft of the manuscript and was involved with the analysis and interpretation of the data. DMB contributed to data interpretation and was involved with extensive writing/editing of the paper.

Provenance and peer review Commissioned; externally peer reviewed.

\section{REFERENCES}

1. World Health Organization. WHO Report on the Global Tobacco Epidemic, 2008: The MPOWER Package. Geneva: WHO press, 2008.

2. Ezzati M, Lopez AD. Smoking and oral tobacco use. In: Ezzati M, Lopez AD, Rodgers A, et al. eds. Comparative Quantification of Health Risks for the Year 2000. Geneva: WHO, 2004:883-957. http://www.who.int/healthinfo/globalburdendisease/cra/en/ (accessed 3 Mar 2011).

3. Chaloupka FJ, Jha P, Corrao MA, et al. Global efforts for reducing the burden of smoking. Disease Management \& Health Outcomes 2003;11:647-61.

4. WHO Framework Convention on Tobacco Control (FCTC). http://whqlibdoc.who.int/ publications/2003/9241591013.pdf (accessed 3 Mar 2011)

5. Irvin JE, Brandon TH. The increasing recalcitrance of smokers in clinical trials. Nicotine Tob Res 2000:2:79-84.

6. Joseph AM, Hennrikus D, Thoele MJ, et al. Community tobacco control leaders' perceptions of harm reduction. Tob Control 2004;13:108-13.

7. Stratton K, Shetty P, Wallace R, et al, eds. Clearing the Smoke: Assessing the Science Base for Tobacco Harm Reduction. Washington, DC: National Academy Press, 2001

8. Warner KE. Tobacco harm reduction: promise and perils. Nicotine Tob Res 2002;4 (Suppl 2):S61-71.

9. Hatsukami DK, Slade J, Benowitz NL, et al. Reducing tobacco harm: research challenges and issues. Nicotine Tob Res 2002;4(Suppl 2):S89-101.

10. Foulds J, Ramstrom L, Burke M, et al. Effect of smokeless tobacco (snus) on smoking and public health in Sweden. Tob Control 2003:12:349-59.

11. Ramström LM, Foulds J. Role of snus in initiation and cessation of tobacco smoking in Sweden. Tob Control 2006:15:210-14.

12. Mejia $\mathbf{A B}$, Ling PM, Glantz SA. Quantifying the effects of promoting smokeless tobacco as a harm reduction strategy in the USA. Tob Control 2010;19:297-305.

13. Fox BJ, Cohen JE. Tobacco harm reduction: a call to address the ethical dilemmas Nicotine Tob Res 2002;4(Suppl 2):S81-7.

14. Martin EG, Warner KE, Lantz PM. Tobacco harm reduction: what do the experts think? Tob Control 2004;13:123-8.

15. Roche AM. Harm reduction and smoking among indigenous Australians. Drug Alcohol Rev 1997;16:91-3.

16. Bedi R, Scully C. Tobacco control-debate on harm reduction enters new phase as India implements public smoking ban. Lancet Oncol 2008;9:1122-3.

17. Idris AM, Ibrahim SO, Vasstrand EN, et al. The Swedish snus and the Sudanese toombak: are they different? Oral Oncol 1998:34:558-66

18. Gupta PC, Pednekar MS, Parkin DM, et al. Tobacco associated mortality in Mumbai (Bombay) India. Results of the Bombay cohort study. Int J Epidemiol 2005; 34:1395-402.

19. Ayo-Yusuf OA, Reddy PS, Van den Borne BW. Association of snuff use with chronic bronchitis among South African women: implications for tobacco harm reduction. Tob Control 2008;17:99-104

20. Scientific Committee on Emerging and Newly Identified Health Risks (SCENIHR). Opinion on: Health Effects of Smokeless Tobacco Products. http://www. tobaccoharmreduction.org/scenihr.pdf (accessed 4 May 2011)

21. International Agency for Research on Cancer. Smokeless Tobacco and Some Tobacco-specific N-nitrosamines. In: IARC Monographs on the Evaluation of Carcinogenic Risks to Humans, Volume 89. Lyon: IARC, 2007.

22. Stanfill SB, Connolly GN, Zhang L, et al. Global surveillance of oral tobacco products: total nicotine, unionized nicotine and tobacco-specific N-nitrosamines. Tob Control 2011;20:e2

23. McNeil A, Bedi R, Islam S, et al. Level of toxins in oral tobacco products in the UK Tob Control 2006; 15:64-7.

24. Boffetta $\mathbf{P}$, Hecht $\mathrm{S}$, Gray N, et al. Smokeless tobacco and cancer. Lancet Oncol 2008:9:667-75.

25. Lee PN, Hamling J. Systematic review of the relation between smokeless tobacco and cancer in Europe and North America. BMC Med 2009;7:36.

26. World Health Organization. WHO Study Group on Tobacco Product Regulation. Report on Setting Regulatory Limits for Carcinogens In Smokeless Tobacco. Report on the Scientific Basis of Tobacco Product Regulation: Third Report of a WHO Study Group. WHO Technical Report Series No. 955. Geneva: WHOpress, 2009:23-8.

27. Lee PN. Circulatory disease and smokeless tobacco in Western populations: a review of the evidence. Int J Epidemiol 2007:36:789-804.

28. Boffeta $\mathbf{P}$, Straif K. Use of smokeless tobacco and risk of myocardial infarction and stroke: systematic review with meta-analysis. BMJ 2009;339:b3060.

29. Yatsuya H, Folsom AR; ARIC Investigators. Risk of incident cardiovascular disease among users of smokeless tobacco in the Atherosclerosis Risk in Communities (ARIC) study. Am J Epidemiol 2010;172:600-5.

30. Hergens MP, Lambe M, Pershagen G, et al. Smokeless tobacco and the risk of stroke. Epidemiology 2008;19:794-9.

31. Teo KK, Ounpuu S, Hawken S, et al; INTERHEART Study Investigators. Tobacco use and risk of myocardial infarction in 52 countries in the INTERHEART study: a casecontrol study. Lancet 2006;368:647-58.
32. England LJ, Levine RJ, Mills JL, et al. Adverse pregnancy outcomes in snuff users. Am J Obstet Gynecol 2003;189:939-43.

33. Gupta PC, Subramoney S. Smokeless tobacco use and risk of stillbirth: a cohort study in Mumbai, India. Epidemiology 2006;17:47-51.

34. Wikström AK, Stephansson 0, Cnattingius S. Tobacco use during pregnancy and preeclampsia risk: effects of cigarette smoking and snuff. Hypertension 2010;55:1254-9.

35. Steyn $\mathbf{K}$, De Wet T, Saloojee $\mathrm{Y}$, et al. The influence of maternal cigarette smoking, snuff use and passive smoking on pregnancy outcomes: the birth to ten study. Paediatr Perinat Epidemiol 2006;20:90-9.

36. Simen-Kapeu A, La Ruche G, Kataja V, et al. Tobacco smoking and chewing as risk factors for multiple human papillomavirus infections and cervical squamous intraepithelial lesions in two countries (Cote d'Ivoire and Finland) with different tobacco exposure. Cancer Causes Control 2009;20:63-70.

37. Tomar SL. Is use of smokeless tobacco a risk factor for cigarette smoking? The US experience. Nicotine Tob Res 2003;5:561-9.

38. Severson HH, Forrester KK, Biglan A. Use of smokeless tobacco is a risk factor for cigarette smoking. Nicotine Tob Res 2007;9:1331-7.

39. O'Connor RJ, Kozlowski LT, Flaherty BP, et al. Most smokeless tobacco use does not cause cigarette smoking: results from the 2000 National Household Survey on drug abuse. Addict Behav 2005;30:325-36.

40. Timberlake DS, Huh J, Lakon CM. Use of propensity score matching in evaluating smokeless tobacco as a gateway to smoking. Nicotine Tob Res 2009;11:455-62

41. Stenbeck M, Hagquist $C$, Rosén $M$. The association of snus and smoking behaviour: a cohort analysis of Swedish males in the 1990s. Addiction 2009:104:1579-85.

42. Ayo-Yusuf OA, Connolly G. Role of Smokeless Tobacco Use in Smoking Initiation and Cessation Among South African Adolescents: a 4-year Longitudinal Study. Maryland: Oral presentation at the Society for Research on Nicotine \& Tobacco, 2010. (Abstract \# P18-2). http://www.srnt.org/conferences/past/2010/pdf/2010_SRNT Proceedings.pdf (assessed 5 May 2011).

43. Lund KE, McNeill A, Scheffels J. The use of snus for quitting smoking compared with medicinal products. Nicotine Tob Res 2010;12:817-22

44. Tønnesen P, Mikkelsen K, Bremann L. Smoking cessation with smokeless tobacco and group therapy: an open, randomized, controlled trial. Nicotine Tob Res 2008; 10:1365-72.

45. Lindström M, Isacsson S0; Malmö Shoulder-Neck Study Group. Smoking cessation among daily smokers, aged 45-69 years: a longitudinal study in Malmö, Sweden. Addiction 2002:97:205-15.

46. Gilljam H, Galanti MR, Pharmacia AB; Swedish Cancer Society. Role of snus (oral moist snuff) in smoking cessation and smoking reduction in Sweden. Addiction 2003:98:1183-9.

47. Lindström M. Nicotine replacement therapy, professional therapy, snuff use and tobacco smoking: a study of smoking cessation strategies in southern Sweden. Tob Control 2007:16:410-16.

48. Lundqvist G, Sandström H, Ohman A, et al. Patterns of tobacco use: a 10-year follow-up study of smoking and snus habits in a middle-aged Swedish population. Scand J Public Health 2009;37:161-7.

49. Carpenter CM, Connolly GN, Ayo-Yusuf OA, et al. Developing smokeless tobacco products for smokers: an examination of tobacco industry documents. Tob Control 2009; 18:54-9

50. McClave-Regan AK, Berkowitz J. Smokers who are also using smokeless tobacco products in the US: a national assessment of characteristics, behaviours and beliefs of 'dual users'. Tob Control 2011;20:239-42.

51. O'Connor RJ, Norton KJ, Bansal-Travers M, et al. US smokers' reactions to a brief trial of oral nicotine products. Harm Reduct $\mathrm{J}$ 2011:8:1.

52. Tomar SL, Alpert HR, Connolly GN. Patterns of dual use of cigarettes and smokeless tobacco among US males: findings from national surveys. Tob Control 2010;19:104-9.

53. Klesges RC, Sherrill-Mittleman D, Ebbert JO, et al. Tobacco use harm reduction, elimination, and escalation in a large military cohort. Am J Public Health 2010;100:2487-92.

54. Rantao M, Ayo-Yusuf OA. Dual use of cigarettes and smokeless tobacco among South African adolescents. Am J Health Behav 2012:36:124-33.

55. Global Adult Tobacco Survey (GATS) India: 2009-2010. http://www.searo.who.int/ LinkFiles/Regional_Tobacco_Surveillance_System_GATS_India.pdf (accessed 5 May 2011).

56. Desalu 00, Iseh KR, Olokoba AB, et al. Smokeless tobacco use in adult Nigerian population. Niger J Clin Pract 2010;13:382-7. http://www.njcponline.com/temp/ NigerJClinPract134382-535445_145224.pdf (accessed 5 Sep 2011).

57. Usmanova G, Neumark $Y$, Baras $M$, et al. Patterns of adult tobacco use in Uzbekistan. Eur J Public Health. Published Online First: 9 September 2011. doi:10.1093/eurpub/ckr125

58. Norberg M, Lundqvist G, Nilsson $\mathbf{M}$, et al. Changing patterns of tobacco use in a middle-aged population: the role of snus, gender, age, and education. Glob Health Action 2011;4. doi:10.3402/gha.v4i0.5613.

59. Engström K, Magnusson C, Galanti MR. Socio-demographic, lifestyle and health characteristics among snus users and dual tobacco users in Stockholm County, Sweden. BMC Public Health 2010;10:619.

60. Frost-Pineda K, Appleton S, Fisher M, et al. Does dual use jeopardize the potentia role of smokeless tobacco in harm reduction? Nicotine Tob Res 2010; 12:1055-67. 
61. Rosendahl KI, Galanti MR, Gilliam H. Trajectories of smokeless tobacco use and of cigarette smoking in a cohort of Swedish adolescents: differences and implications. Nicotine Tob Res 2008; 10:1021-7.

62. Shiffman S, Gitchell J, Rohay JM, et al. Smokers' preferences for medicinal nicotine vs smokeless tobacco. Am J Health Behav 2007;31:462-72.

63. Wilson N, Borland R, Weerasekera D, et al. Smoker interest in lower harm alternatives to cigarettes: national survey data. Nicotine Tob Res 2009:11:1467-73.

64. Gartner CE, Jimenez-Soto EV, Borland R, et al. Are Australian smokers interested in using low-nitrosamine smokeless tobacco for harm reduction? Tob Control 2010;19:451-6.

65. Timberlake DS. Are smokers receptive to using smokeless tobacco as a substitute? Prev Med 2009:49:229-32.

66. Connolly GN. The marketing of nicotine addiction by oral snuff manufacturer. Tob Control 1995:4:73-9.

67. Zhu SH, Wang JB, Hartman A, et al. Quitting cigarettes completely or switching to smokeless tobacco: do US data replicate the Swedish results? Tob Control 2009:18:82-7.

68. Alternative to Cigarettes Unrolled. http://articles.timesofindia.indiatimes.com/200202-23/pune/27122004_1_snus-oral-cancer-tobacco (accessed 14 Nov 2011).

69. Chapman S. Public Health Advocacy and Tobacco Control: Making Smoking History. 1st edn. Oxford: Blackwell, 2007.

70. Curry LE, Pederson LL, Stryker JE. The changing marketing of smokeless tobacco in magazine advertisements. Nicotine Tob Res 2011;13:540-7.

71. Timberlake DS, Pechmann C, Tran SY, et al. A content analysis of Camel snus advertisements in print media. Nicotine Tob Res 2011:13:431-9.
72. Gartner $\mathbf{C E}$, Hall WD, Chapman S, et al. Should the health community promote smokeless tobacco (snus) as a harm reduction measure? PLoS Med 2007; 4:e185

73. Peer N, Bradshaw D, Laubscher R, et al. Trends in adult tobacco use from two South African demographic and health surveys conducted in 1998 and 2003. S Afr Med J 2009:99:744-9.

74. Nilsson S, Carstensen JM, Pershagen G. Mortality among male and female smokers in Sweden: a 33 year follow up. J Epidemiol Community Health 2001:55:825-30.

75. Nordgren $\mathbf{P}$, Ramstrom L. Moist snuff in Sweden-tradition and evolution. $\mathrm{Br} \mathrm{J}$ Addict 1990;85:1107-12.

76. Tomar SL, Connolly GN, Wilkenfield J, et al. Declining smoking in Sweden: is Swedish match getting the credit for Swedish tobacco control's efforts? Tob Control 2003;12:368-71.

77. World Health Organization (WHO) Country Office for Bangladesh. Global Adult Tobacco Survey: Bangladesh Report. Bangladesh, 2009. http://www.whoban.org/ pdf/Global\%20Adult\%20Tobacco\%20Survey\%20Bangladesh\%20Report\%202009.pdf (accessed 15 Nov 2011).

78. Murukutla N, Turk T, Prasad CV, et al. Results of a national mass media campaign in India to warn against the dangers of smokeless tobacco consumption. Tob Control 2012:21:12-17.

79. WHO Report on the Global Tobacco Epidemic, 2011. http://www.who.int/tobacco/ global report/2011/appendix viii/en/index.html (accessed 15 Nov 2011).

80. Yang GH, Li Q, Wang CX, et al. Findings from 2010 global adult tobacco survey: implementation of MPOWER policy in China. Biomed Environ Sci 2010:23:422-9. 